Original article

\title{
Arranging the questionnaire to identify brucellosis risk factors in Western Kazakhstan
}

\author{
Aisha Urazaeva ${ }^{1}$, Saule Balmagambetova ${ }^{1}$, Zhumabek Bekenov ${ }^{2}$, Saltanat Urazaeva ${ }^{1}$, Kymbat Tussupkalieva ${ }^{1}$ \\ ${ }^{1}$ West Kazakhstan Marat Ospanov Medical University, Aktobe, Kazakhstan; \\ ${ }^{2}$ National Center of Public Health, Nur-Sultan, Kazakhstan
}

Received 24 March 2020, Revised 11 October 2020, Accepted 4 November 2020

(C) 2020, Urazaeva A., Balmagambetova S., Bekenov Z., Urazaeva S., Tussupkalieva K.

(C) 2020, Russian Open Medical Journal

Abstract: Background - In some Kazakhstan regions, the epidemic situation on brucellosis remains tense, despite the observed trend to decrease in the incidence: 5.5 per 100,000 population by 2018 vs. 6.2 in 2017.

The article aims at presenting the steps of preparing the brucellosis questionnaire to identify infection risk factors.

Methods - A questionnaire is developed based on the Health Belief Model to arrange interviews among the adult population of the Aktobe region. Stages of the drafting process included: 1) review of relevant literature sources; 2) assessment of the target audience to calculate N (number of interviewees); 3) development of the questionnaire itself; 4) testing the tool in focus-groups; 5) validation through Cronbach's alpha $(\alpha)$ calculation to reach the internal consistency of the questionnaire; 6$)$ final editing of the survey tool. The Cronbach's alpha was calculated using the item-analysis in the SPSS Modeler.v.25.

Results - The designed questionnaire consisted of the three domains with twenty-two questions of the semi-closed type and underwent testing in the focus-group of ninety-eight livestock owners. A preliminary analysis revealed five items with unsatisfactory mean values, which were either modified or deleted so that the $\alpha$ resulted in 0.71 (moderately reliable). The adjusted tool eventually contained seventeen items (questions).

Conclusion - A simple design and adequate validation of the survey tool should facilitate information on population awareness of the clinical symptoms and paths of brucellosis infection transmission. Data on accepted practice on caring for livestock in private households across the region also become available for analysis owing to the presented questionnaire.

Keywords: Brucellosis, risk factors, questionnaire, Aktobe region, Kazakhstan.

Cite as Urazaeva A, Balmagambetova S, Bekenov Z, Urazaeva S, Tussupkalieva K. Arranging the questionnaire to identify Brucellosis risk factors in Western Kazakhstan. Russian Open Medical Journal 2020; 9: e0407.

Correspondence to Saule Balmagambetova. Address: West Kazakhstan Marat Ospanov Medical University. 68, Maresyev Street, 030019, Aktobe, Kazakhstan. Phone: +77055794637. Fax: +77132563201. E-mail: sau3567@gmail.com.

\section{Introduction}

According to the World Health Organization (WHO), brucellosis is referred to as one of the seven "neglected" zoonotic diseases, notwithstanding that it is a severe public health problem due to physical suffering and reduced work capacity of infected people. Besides, the detection of brucellosis in humans involves the need to dispose of livestock with the identified infection [1].

Increased incidence rates in human brucellosis are commonly inherent to countries with developed livestock farming. Reportedly, Central Asia countries show one of the highest global incidence rates of brucellosis in humans [2]. According to data from the Regional meeting of the Food and Agriculture Organization of the United Nations (FAO), the list of twenty-five countries with the highest incidence rates includes seven postSoviet states endemic for brucellosis. One hundred and sixteen cases per one million of the population were recorded in Kazakhstan in 2013, as FAO experts said [3]. Brucellosis is a primary zoonotic infection in Kazakhstan. However, there are limited data on its incidence in humans and animals. Moreover, there is no detailed overview of the Kazakhstan brucellosis control and eradication programs [4].

Brucellosis in humans is a zoonosis with variform clinical symptoms that occurs throughout all the inhabited continents. In humans, the disease is mainly caused by Brucella melitensis, followed by $B$. suis, while $B$. abortus is considered the mildest type of brucellosis. Infected domestic animals, especially cattle, sheep, goats, and also wild animals, are a natural reservoir of microbes and a source of infection. Specialists dealing with livestock are being particularly vulnerable - veterinarians, farmers, and workers of slaughterhouses and meat processing enterprises [5].

High-risk exposures imply working in specialized laboratories and include: handling infected tissue without respiratory protection, direct contact with infected blood and body fluids, mucosal exposure to aerosolized Brucella organisms after an aerosol-generating procedure, handling specimens on an open bench, or being within 5 feet of this manipulation; having direct skin contact with a culture; or being present in the laboratory room during any procedure that might result in widespread aerosolization of an isolate, etc. Low-risk exposures include being 
present in the operating or laboratory room without activities qualifying as a high-risk exposure [6]. It has also been proven that the disease cases are more likely to occur in groups that practice dangerous social and cultural activities, such as consuming raw blood and dairy products and slaughtering animals near the living area of households [7].

Despite definite progress in preventing the disease, the epidemic situation in some regions of Kazakhstan remains unfavorable. Notwithstanding, a tendency to decrease in the incidence rates emerged: 998 cases or 5.5 per 100 thousand of the population recorded in 2018 compared to 1,104 (6.2) in 2017. These data were taken from the "Analysis of the epizootic and epidemic situation of brucellosis in the Republic of Kazakhstan by 2018 and tasks for 2019" prepared by the Kazakh National Center of Public Health. In the Aktobe region, according to local official reports, the corresponding index for 2018 was 2.4 (abs. 21), in $2017-2.8$ (abs. 24). Private farm animals are the primary sources of brucellosis in the country.

However, large-scale studies to identify risk factors for brucellosis onset among the general population, including private livestock owners, have not yet been conducted in Kazakhstan. National researchers have not previously presented a methodology for such studies. As the FAO brucellosis surveillance experts emphasized in their guidelines, "...In any disease control or eradication program, decisions have to be based on information. If this information is faulty or biased, there is a greater likelihood that incorrect decisions will be made." [8].

As known, the survey is the most cost-effective and the fastest tool for determining needs and perceptions and the awareness of the target audience. Based on developed questionnaires, analysts can trace very noticeable differences depending on countries' economic conditions in which these tools are in use. In highincome countries, computer-assisted interviews (CASI) and postal and telephone surveys are in service, which provides better confidentiality for the respondent, despite the relatively low response rate (65\% is considered acceptable). A direct interview is the option of choice when some difficulties in obtaining and interpreting information may occur. A personal interview provides opportunities for better control, observation, and on-site verification. Such interviews are often used in low/middle-income countries, where there are many poorly educated people, or in locales where social and cultural practices vary from the western way of life [7, 9-11].

As to the models for designing a questionnaire, the two approaches are the most popular. One of them is applying the theory of planned behavior (TPB) developed by Aizen: "...friendly attitude makes a person more attentive to recommendations made by significant people from his surroundings." [12]. The second approach is in following the recommendations of Robert de Wellis in his book "Scale development" based on the Health Belief Model (HBM) [13]. This approach has become more prevalent in development of questionnaires to identify the significance of risk factors and the target audience's awareness concerning the studied problem.

Perfecting preventive measures in the Aktobe region first requires revealing the public awareness of brucellosis symptoms to rank human infection risk factors. Accomplishing this task calls for designing an appropriate tool for interviewing the population.
Thus, our purpose is to present the stages of development and validation of a brucellosis questionnaire to identify risk factors for infection in the adult population of the Aktobe region.

The following tasks are to be solved:

i) analyzing relevant sources to determine the target audience of the survey and the method of developing the questionnaire (model);

ii) designing a draft of the survey tool;

iii) validation and adjusting the tool by preliminary testing in focus groups, with the Cronbach's alpha calculation.

\section{Material and Methods}

\section{Study setting}

The study was performed at the Department of Epidemiology in West Kazakhstan Medical University together with specialists from the National Center of Public Health of Kazakhstan.

The study's design and protocol were approved by the University's IRB (No. 32/6, 09/06/2019). The work was carried out under the STROBE observational research checklist. An informed consent form was developed by the WHO recommendations. The version of a questionnaire for testing in the focus group and the informed consent form were drafted in two languages, Russian and Kazakh, to provide a choice at an interviewee's request.

\section{Consecutive stages of the work}

1) Analysis of relevant literature sources. In total, 15 publications in the reviewed journals for the period 2015-2019 were analyzed on the risk factors and the surveys' findings, mainly farmers and cattle owners. The geography of papers covered: Africa (Kenya, Uganda, Rwanda, Ethiopia) [7, 9-11], Asia (Pakistan, Iran, Mongolia, Thailand, Tajikistan, Jordan) [14-22], Europe (Portugal) [23], and also Kazakhstan [3, 4].

2) Assessment of the target audience to calculate $N$ (number of interviewees). Analysis of cited publications with valid results revealed a wide range in the number of interviewees, from 70 to 537. Based on the regional statistical office data on the population by districts and the number of livestock households, the planned interview sample size resulted in 700-768 respondents (households). The selection of districts for the proposed survey was performed based on the proportion of the livestock-free households and the livestock owners:

Oiyl district - population in total 6,631; livestock households 2,113; sample size - 118;

Mugalzhar district - population in total 43,921; livestock households $-3,043$; sample size -174 ; Temir district - population in total 23,657; livestock households $-3,064$; sample size -163 ;

Bayganin district - population in total 13,214; livestock households - 3,083; sample size - 150;

Shalkar district - population in total 28,602 ; livestock households $-3,889$; sample size -163 .

Thus, the population-based method was used to determine the sample size of 700-768 households.

3) Development of the present questionnaire. Based on a preliminary analysis of the target audience according to the statistics (the number of livestock households, the level of education, and professional status of the rural population), we decided to develop a questionnaire based on the Health Belief 
Model (HBM), as the main goal of the study was to identify the degree of public awareness on brucellosis infection risk factors. For the initial version of the questionnaire, 22 semi-closed questions were drafted.

4) Testing the developed tool in focus groups. Testing the questionnaire was run across the two districts of the Aktobe region: Oiyl (agricultural area, almost all inhabitants are the livestock owners) and Mugalzhar (industrial area with a mixed population, including both livestock owners and livestock-free householders).

5). Validation through Cronbach's alpha calculation ( $\alpha$ ) to adjust the internal consistency of the questions. In line with the commonly accepted validation standards, the questionnaire was subjected to a statistical analysis of the internal consistency with the definition of the Cronbach's alpha according to the formula:

$$
\alpha=N * r /(1+r *(N-1))
$$

where $N$ is the number of survey items, $r$ is the average inter-item correlation coefficient.
The commonly accepted interpreting of Cronbach's alpha results is as follows: from 0 to 0.5 - unacceptable; 0.5-0.6 - poor; 0.6-0.7 - questionable; 0.7-0.8 - acceptable; 0.8-0.9 - good; 0.91.0 - excellent.

The item-analysis was carried out using the SPSS modeler v. 25 (IBM, Armonk, USA).

6). Final editing of the survey tool. After testing the initial version of the questionnaire in focus groups selected with an eye on the representativeness of various strata of the population, and calculating the Cronbach's alpha to identify variables with imperfect inter-item correlation, we performed the final editing of the tool.

\section{Results}

The questionnaire's initial draft consisted of twenty-two items (questions) of the semi-closed type, where each included several options of clearly determined responses. All questions (items) were divided into three domains:

Table 1. The variables (items)' mean values in the initial questionnaire*. $\mathbf{N}$ observations: 55

\begin{tabular}{|c|c|c|}
\hline & Mean & $S D$ \\
\hline Do you own a livestock? Yes/No & 0.315 & 0.482 \\
\hline How much and what kind of livestock do you own? & 1.733 & 0.680 \\
\hline What protective equipment and measures do you use when caring for livestock and cleansing premises for its maintenance? & 3.300 & 1.320 \\
\hline Do you know the clinical symptoms of brucellosis? & 1.933 & 0.854 \\
\hline Have you or someone from your family ever had brucellosis? Yes/No & 0.133 & 0.340 \\
\hline If you or your relatives have had brucellosis, have you practiced self-medication? Yes/No & 0.133 & 0.427 \\
\hline Is it possible to get brucellosis through: (list) & 2.967 & 1.169 \\
\hline Can someone get brucellosis when consuming: (list) & 1.500 & 0.922 \\
\hline Do you take part in a lambing, slaughtering animals, an autopsy of animals corpses, skinning animals? & 1.933 & 0.629 \\
\hline How do you handle the abortion material, stillborn animals, and animal placentas? & 1.767 & 0.616 \\
\hline Do you use hides of animals in everyday life? Yes/No & 0.167 & 0.373 \\
\hline Do you use the wool of animals in everyday life? Yes/No & 0.233 & 0.423 \\
\hline Do you use animal manure to fertilize the garden? Yes/No & 0.667 & 0.471 \\
\hline Where do you get manure to fertilize your garden? & 1.367 & 0.752 \\
\hline When buying livestock products from individuals, do you require a certificate of livestock health? & 1.900 & 0.943 \\
\hline
\end{tabular}

*The dichotomous variables' mean values of $<1.0$ are shown in bold; socio-demographic domain is not included in the analysis; additional explanations on calculations are provided in the Supplement.

Table 2. Cronbach's alpha calculation in the edited version of the questionnaire. Statistics for scale: Mean $=26.0865$. SD 5.32645. N: 98. Alpha: .690607. Standardized alpha: .705330. The average inter-item correl: .159378.

\begin{tabular}{|c|c|c|c|c|c|}
\hline & $\begin{array}{l}\text { Scale mean if } \\
\text { item deleted }\end{array}$ & $\begin{array}{l}\text { Scale variance } \\
\text { if item deleted }\end{array}$ & $\begin{array}{l}\text { SD if item } \\
\text { deleted }\end{array}$ & $\begin{array}{l}\text { Corrected item } \\
\text { total correlation }\end{array}$ & $\begin{array}{c}\text { Alpha } \\
\text { if item deleted }\end{array}$ \\
\hline How much and what kind of farm animals do you own? & 23.990 & 26.490 & 5.147 & 0.304 & 0.639 \\
\hline $\begin{array}{l}\text { What protective equipment and measures do you use when caring for } \\
\text { livestock and cleansing premises for its maintenance? }\end{array}$ & 24.067 & 26.909 & 5.187 & 0.193 & 0.647 \\
\hline $\begin{array}{l}\text { Do you know the clinical symptoms of brucellosis in humans and } \\
\text { animals? }\end{array}$ & 23.212 & 25.705 & 5.070 & 0.071 & 0.651 \\
\hline $\begin{array}{l}\text { If you or your relatives have had brucellosis, have you practiced self- } \\
\text { medication? }\end{array}$ & 26.174 & 24.637 & 5.038 & 0.479 & 0.635 \\
\hline Is it possible to get brucellosis through: (list) & 24.740 & 25.519 & 5.052 & 0.256 & 0.638 \\
\hline Can someone get brucellosis when consuming: (list) & 24.317 & 26.294 & 5.128 & 0.239 & 0.651 \\
\hline $\begin{array}{l}\text { Do you take part in a lambing, slaughtering animals, an autopsy of } \\
\text { animals corpses, skinning animals? }\end{array}$ & 23.856 & 26.835 & 5.180 & 0.183 & 0.637 \\
\hline $\begin{array}{l}\text { How do you handle the abortion material, stillborn animals, and } \\
\text { animal placentas? }\end{array}$ & 24.192 & 25.559 & 5.056 & 0.333 & 0.630 \\
\hline Where do you usually slaughter animals? & 24.558 & 24.458 & 4.946 & 0.474 & 0.612 \\
\hline Do you use wool, hides, and animal manure in everyday life? & 24.308 & 20.328 & 4.509 & 0.634 & 0.597 \\
\hline $\begin{array}{l}\text { When buying livestock products from individuals, do you require a } \\
\text { certificate of livestock health? }\end{array}$ & 23.510 & 20.135 & 4.487 & 0.543 & 0.573 \\
\hline
\end{tabular}

Socio-demographic domain is not included in the analysis 
Table 3. The final version of the questionnaire

\begin{tabular}{|c|c|c|}
\hline № & Questions: & Answers options: \\
\hline & & ersonal data: \\
\hline 2 & Gender & $\begin{array}{l}\text { Male } \\
\text { Female }\end{array}$ \\
\hline 3 & Residence & District center \\
\hline & & Village \\
\hline & & Suburb \\
\hline 4 & Education & Secondary (school) \\
\hline & & Special secondary (college) \\
\hline & & Higher (university) \\
\hline 5 & Occupation & Housewife (unemployed) \\
\hline & & Small business (retail trade of own livestock products) \\
\hline & & Businessman (management of own large livestock company) \\
\hline & & Occupation is related to agriculture or livestock breeding \\
\hline & & Occupation is not related to agriculture or livestock breeding \\
\hline 6 & How many members in your family? & Üp to 4 persons \\
\hline & & Up to 7 persons \\
\hline & & 8 and more \\
\hline$\overline{7}$ & How much and what kind of farm animals do you own? & I do not own any farm animals \\
\hline & & $\begin{array}{l}\text { Cattle and other farm animals in small quantities ( } 1-2 \text { cows, up to } 5 \text { sheep, goats, } \\
\text { camels) }\end{array}$ \\
\hline & & $\begin{array}{l}\text { Cattle and other farm animals in moderate numbers (over } 5 \text { cows, over } 5 \text { sheep, } \\
\text { goats, camels) }\end{array}$ \\
\hline & & Cattle and other farm animals in a large number \\
\hline & Awar & ess on brucellosis: \\
\hline 8 & Do you know the clinical symptoms of brucellosis in & No \\
\hline & humans and animals? & A little bit familiar with this problem, not enough \\
\hline 9 & If you or your relatives have had brucellosis, have you & No, there were no brucellosis patients in the family \\
\hline & practiced self-medication? & Yes, there were sick relatives, but they were treated and observed in the hospital \\
\hline & & $\begin{array}{l}\text { Yes, there were sick family members, and for some time they tried to be treated } \\
\text { on their own, addressing to healers }\end{array}$ \\
\hline 10 & Is it possible to get brucellosis through: & Air and/or soil \\
\hline & & Through the infected food consuming only \\
\hline & & with a sick person only \\
\hline & & contact with a sick animal only \\
\hline & & Through all of the above, except air and soil \\
\hline 11 & Can I get brucellosis when consuming: & Only when eating homemade meat and dairy products \\
\hline & & Through catering only (cafes, street food) \\
\hline & & Possible both through the homemade products and through the catering network \\
\hline & & Possibly through the factory-made products (meat, dairy) \\
\hline & Use of protecti & equipment and measures: \\
\hline 12 & What protective equipment and measures do you use & Don't have farm animals \\
\hline & $\begin{array}{l}\text { when caring for livestock and cleansing premises for its } \\
\text { maintenance? }\end{array}$ & $\begin{array}{l}\text { I carry out disinfection on my own using personal equipment (replaceable } \\
\text { clothes, shoes) }\end{array}$ \\
\hline & & $\begin{array}{l}\text { I carry out disinfection by myself using personal equipment (replaceable clothing, } \\
\text { shoes + mask, gloves mandatorily) }\end{array}$ \\
\hline & & Call disinfectors \\
\hline 13 & Do you take part in a lambing, slaughtering animals, an & No (don't have farm animals) \\
\hline & autopsy of animals corpses, skinning animals? & $\begin{array}{l}\text { I do not hold farm animals, but sometimes I take part at the request of relatives } \\
\text { or acquaintances }\end{array}$ \\
\hline & & Yes, on a regular basis \\
\hline 14 & Where do you usually slaughter animals? & Ido not do it (have no farm animals) \\
\hline & & In my own kitchen \\
\hline & & In my own courtyard \\
\hline & & In a specially equipped zone, under the control of vet service \\
\hline 15 & Do you use wool, hides, animal manure in everyday life? & No \\
\hline & (examples: use manure for the production of adobe or & Sometimes, rarely \\
\hline & fertilize the garden; make products from hides or wool) & Yes, constantly. $\ldots \ldots$ \\
\hline 16 & How do you handle the abortion material, stillborn & I do not take part in a lambing (no livestock) \\
\hline & animals, and animal placentas? & It happens sometimes that I throw this material in household trash \\
\hline & & I recycle it by myself through burning, burying this material \\
\hline & & I invite the veterinary service \\
\hline 17 & When buying livestock products from individuals, do you & No, i do not ask \\
\hline & require a certificate of livestock health? & Did not think about it \\
\hline & & $\begin{array}{l}\text { I thought about it, but do not dare to ask, as it is not commonly accepted } \\
\text { I buy only on large farms with a full package of documents }\end{array}$ \\
\hline & & Yes, always \\
\hline
\end{tabular}


i) domain 1: socio-demographic profile of the respondent; a total of 8 questions;

ii) domain 2: awareness of the disease and paths of transmitting the infection; a total of 5 questions;

iii) domain 3: the use of protective equipment and measures for cattle care; a total of 9 questions.

All questions (variables) were characterized: nominal, categorical, ordinal, etc. For the first testing of the questionnaire in the focus group, 55 participants from the Aktobe suburbs were enlisted. The socio-demographic domain (age, gender, etc.) was not included in the analysis, as this part of data was not correspondent to the questionnaire's target items.

The analysis revealed unsatisfactory mean values of the dichotomous variables, which were shown in Table 1.

To avoid questions in dichotomous mode, one possible solution was designing the two options - for livestock owners and livestock-free individuals. But, given the anticipated difficulties in collecting data throughout the remote areas, we decided either to delete all dichotomous variables with mean values less than 1.0 or modify them to obtain adequate values of more than 1.0 by increasing the answer options up to $3+$

The edited questionnaire of 17 items we eventually tested in the two districts of the Aktobe region - Oiyl and Mugalzhar. In direct interviews, we collected a total of 98 completed questionnaires and calculated the Cronbach's $\alpha$ for adjusting the internal consistency of the items. The results of Cronbach's alpha calculation after editing the items we presented in Table 2 .

Thus, as the standardized $\alpha$ reaches 0.71 (acceptable, moderately reliable), the survey tool may be considered adjusted. It is noteworthy that the $\alpha$ coefficient value can be increased up to 0.9 or higher through increasing the number of questions (items) included. Nevertheless, when designing the survey tool, the target audience's educational level should be kept in mind. If the respondents' education is expected very heterogeneous, the questionnaire pithiness should be achieved through a minimally acceptable number of questions. In the edited version, the questionnaire contained 17 questions, with no less than 3 answer options for each item (Table 3).

\section{Discussion}

As the main goal of designing the questionnaire was obtaining data on awareness of the region inhabitants in key risk factors for brucellosis transmission, we selected similar papers on the issue. Analyzing the literature sources revealed a common unsatisfactory level of awareness in farmers (the livestock owners) from low- and middle-income countries regarding the brucellosis transmission paths. According to data from the African and Mongolian authors $[7,9-11,18]$, more than $90 \%$ of interviewed farmers did not know about safety precautions when handling aborted material. Jordanian researchers [22] described the custom of feeding the dogs with aborted material and indicated its high chance for seropositivity (OR $8.0,95 \% \mathrm{Cl}: 3.5-18.1$ ), which was also confirmed in studies from Thailand $[19,20]$. Researchers from Pakistan found that the herds with five to eight or more buffaloes (bulls) have more likelihood to get brucellosis infected than the herds with fewer buffaloes, up to four (OR 3.81, 95\% Cl 1.51-9.58) [14]. A survey in Tajikistan found out that about $85 \%$ of farmers never heard about brucellosis, $17 \%$ sold unpasteurized dairy products to consumers directly, and nearly $30 \%$ of households constantly consumed unpasteurized dairy products themselves [21]. Meanwhile, a European study (Portugal), presented quite indicative findings. Up to $80 \%$ of farmers were aware of the association of brucellosis with cattle and were able to recognize the clinical symptoms in humans. Conversely, $25.3 \%$ of those who were not concerned with livestock breeding knew almost nothing about the disease [23]. Such a difference in awareness between the livestock owners and livestock-free individuals led to the necessity of including all population strata in the survey, and we strived to reach wide coverage through the interview performance both in agriculture areas and industrial districts of the region.

Overall, there are a few modalities to conduct a survey which are applied depending on the research goal. For instance, the fourstage PRECEDE model was designed in 2016 and used mainly to solve the task on of assessing the health and quality of life in respondents living in areas endemic for brucellosis [15]. Studying the Iranian researchers' papers who developed HBM-based questionnaires with the number of items within 25 show that this particular model is optimal. HBM, unlike the other models, can reveal the degree of public awareness of the brucellosis infection risk factors. Their results show that educational intervention is needed to increase awareness of brucellosis risks, and HBM-based education can promote knowledge, attitude, and behavior on disease prevention $[16,17]$. This model can be used as a framework for designing educational interventions, which should become the next step in brucellosis prevention in Kazakhstan.

\section{Conclusion}

Based on the relevant literature sources and adequately validated survey tool will allow for obtaining information on awareness of brucellosis clinical symptoms and paths of the infection transmission and how the Aktobe region inhabitants from the private households practice the protective measures of caring for livestock.

\section{Funding}

The authors declare that there was no funding for the present work.

\section{Acknowledgment}

The authors' team thanks to the statistician of the West Kazakhstan Medical University, Ms. Zhanylsyn Utepova, for assistance in the statistical processing of the positional analysis results.

\section{Conflict of interest}

The authors declare that they have no conflict of interest.

\section{Ethical approval}

All procedures performed in this study involving human participants followed the institutional and national research committee's ethical standards and the 1964 Helsinki declaration and its later amendments or comparable ethical standards.

\section{References}

1. World Health Organization. Neglected tropical diseases: hidden successes, emerging opportunities. Dr Savioli L, ed. WHO Press, 2009: 10-13. https://www.who.int/neglected diseases/resources/9789241598705/ en/. 
2. Pappas G, Papadimitriou P, Akritidis N, Christou L, Tsianos EV. The new global map of human brucellosis. Lancet Infect Dis 2006; 6(2): 91-99. https://doi.org/10.1016/s1473-3099(06)70382-6.

3. FAO. 2015. Regional workshop on brucellosis control in Central Asia and Eastern Europe. FAO Animal Production and Health Report No. 8. Rome, Italy. Russian. http://www.fao.org/3/a-i4387r.pdf.v

4. Shevtsova E, Shevtsov A, Mukanov K, Filipenko M, Dinara Kamalova, Sytnik I, et al. Epidemiology of Brucellosis and Genetic Diversity of Brucella abortus in Kazakhstan. PLoS One 2016; 11(12): e0167496. https://doi.org/10.1371/journal.pone.0167496.

5. Galińska EM, Zagórski J. Brucellosis in humans - etiology, diagnostics, clinical forms. Ann Agric Environ Med 2013; 20(2): 233-238. https://pubmed.ncbi.nlm.nih.gov/23772567/.

6. Washington State Department of Health. DOH \# 420-048. Brucellosis Reporting and Surveillance Guidelines. December 2019. https://www.doh.wa.gov/Portals/1/Documents/5100/420-048Guideline-Brucellosis.pdf.

7. Njeru J, Wareth G, Melzer F, Henning K, Pletz MW, Heller R, et al. Systematic review of brucellosis in Kenya: disease frequency in humans and animals and risk factors for human infection. BMC Public Health 2016; 16(1): 853. https://doi.org/10.1186/s12889-016-3532-9.

8. Guidelines for coordinated human and animal brucellosis surveillance. Robinson A, ed. FAO Animal Production And Health Paper. 156. Rome, 2003; 46 p. http://www.fao.org/3/a-y4723e.pdf.

9. Chaka H, Aboset G, Garoma A, Gumi B, Thys E. Cross-sectional survey of brucellosis and associated risk factors in the livestock-wildlife interface area of Nechisar National Park, Ethiopia. Trop Anim Health Prod 2018; 50(5): 1041-1049. https://doi.org/10.1007/s11250-0181528-4.

10. Ndazigaruye G, Mushonga B, Kandiwa E, Samkange A, Segwagwe BE. Prevalence and risk factors for brucellosis seropositivity in cattle in Nyagatare District, Eastern Province, Rwanda. J S Afr Vet Assoc 2018; 89(0): e1-e8. https://doi.org/10.4102/jsava.v89i0.1625.

11. Kansiime C, Atuyambe LM, Asiimwe BB, Mugisha A, Mugisha S, Guma $V$, et al. Community Perceptions on Integrating Animal Vaccination and Health Education by Veterinary and Public Health Workers in the Prevention of Brucellosis among Pastoral Communities of South Western Uganda. PLoS One 2015; 10(7): e0132206. https://doi.org/10.1371/journal.pone.0132206.

12. Ajzen I. The theory of planned behavior. Organ Behav Hum Decis Process 1991; 50(2): 179-211. https://doi.org/10.1016/07495978(91)90020-T.

13. DeVellis RF. Scale Development: Theory and Applications. 4th ed. SAGE Publications, Inc. 2016: 26-31. https://us.sagepub.com/enus/nam/scale-development/book246123.

14. Arif S, Thomson PC, Hernandez-Jover M, McGill DM, Warriach HM, Hayatt $K$, et al. Bovine brucellosis in Pakistan; an analysis of engagement with risk factors in smallholder farmer settings. Vet Med Sci 2019; 5(3): 390-401. https://doi.org/10.1002/vms3.165.

15. Jahangiry L, Khazaee-Pool M, Mahdavi B, Ponnet K, Sarbakhsh P. Preventive factors related to brucellosis among rural population using the PRECEDE model: an application of path analysis. Trop Anim Health Prod 2019; 51(2): 419-428. https://doi.org/10.1007/s11250-018-17082.

16. Nasirzadeh M, Aligol M, Hafezi Bakhtiari M, Eslami AA. The Effects of Education on Promoting Knowledge, Beliefs and Preventive Behaviors on Brucellosis among Women: Applying a Health Belief Model. Jundishapur J Health Sci 2014;6(2):343-349. http://citeseerx.ist.psu.edu/viewdoc/download?doi=10.1.1.864.7182\& rep=rep1\&type=pdf.

17. Eskandari Z, Bashirian S, Barati M, Soltanian AR, Hazavehi SMM. The Effect of Educational Program Based on the Health Belief Model on Brucellosis Preventive Behaviors among Traditional Ranchers in Rural Areas of Hamadan Province. J Educ Community Health 2017; 3(4): 1623. Persian. http://jech.umsha.ac.ir/article-1-176-en.html.
18. Bat-Erdene D, Chuang YC, Chuang KY. Brucellosis knowledge and preventive practices among herders in Western Mongolia. Zoonoses $\begin{array}{llll}\text { Public Health } & \text { 2019; } & \text { 66(1): } & \end{array}$ https://doi.org/10.1111/zph.12545.

19. Peck ME, Jenpanich C, Amonsin A, Bunpapong N, Chanachai K, Somrongthong $\mathrm{R}$, et al. Knowledge, Attitudes and Practices Associated with Brucellosis among Small-Scale Goat Farmers in Thailand. Agromedicine 2019; 24(1): 56-63. https://doi.org/10.1080/1059924x.2018.1538916.

20. Noviana C, Wibawan IWT, Sudarnika E. Knowledge, attitude, and practices of breeding kennel owner regarding canine brucellosis prevention and controlling on imported dogs. Jurnal Veteriner 2016 17(2): 265-273. https://doi.org/10.19087/jveteriner.2016.17.2.265.

21. Lindahl E, Sattorov N, Boqvist S, Magnusson U. A Study of Knowledge, Attitudes and Practices Relating to Brucellosis among Small-Scale Dairy Farmers in an Urban and Peri-Urban Area of Tajikistan. PLoS One 2015; 10(2): e0117318. https://doi.org/10.1371/journal.pone.0117318.

22. Musallam II, Abo-Shehada M, Omar M, Guitian J. Cross-sectional study of brucellosis in Jordan: Prevalence, risk factors and spatial distribution in small ruminants and cattle. Prev Vet Med 2015; 118(4): 387-396. https://doi.org/10.1016/j.prevetmed.2014.12.020.

23. Díez JG, Coelho AC. An evaluation of cattle farmers' knowledge of bovine brucellosis in northeastern Portugal. J Infect Public Health 2013; 6(5): 363-369. https://doi.org/10.1016/j.jiph.2013.04.008.

\section{Authors:}

Aisha Urazayeva - PhD student, Department of Epidemiology, West Kazakhstan Marat Ospanov Medical University, Aktobe, Kazakhstan. https://orcid.org/0000-0001-5978-2957.

Saule Balmagambetova - MD, PhD, Associate Professor, Department of Oncology, West Kazakhstan Marat Ospanov Medical University, Aktobe, Kazakhstan. https://orcid.org/0000-0003-4080-5383.

Zhumabek Bekenov - MD, PhD, Head of the Department of Infectious Diseases Prevention, National Center of Public Health, Nur-Sultan, Kazakhstan. https://orcid.org/0000-0002-3412-5309.

Saltanat Urazayeva - MD, PhD, Head of the Epidemiology Department West Kazakhstan Marat Ospanov Medical University, Aktobe, Kazakhstan. https://orcid.org/0000-0002-4773-0807.

Kymbat Tussupkaliyeva - MD, PhD, Associate Professor, Epidemiology Department, West Kazakhstan Marat Ospanov Medical University, Aktobe, Kazakhstan. https://orcid.org/0000-0002-6980-378X. 


\section{Supplement. Brief explanations of how the data processed}

The item-analysis was carried out using the SPSS modeler v.25 (IBM, Armonk, USA).

In SPSS.v.25, reliability analysis is performed using the standard deviation (SD). Yet, in the initial version of the Questionnaire, there were dichotomous variables for which using the standard error (SE) of the mean would be optimal. But those variables which gave the mean less than 1 (dichotomous) were eventually removed (Table 1).

In the Results section, it is explained that these items have either been deleted or rephrased: " ... we decided either to delete all dichotomous variables with mean values less than 1.0 or modify them to obtain adequate values of more than 1.0 by increasing the answer options up to $3+. "$

The Questionnaire contains multiple choice, which implies a strict ranking of answer options from minimum to maximum or vice versa.

When preparing the answer options, we were guided by the Leslie G. Portney and Mary P. Watkins book (pages 606-607), who brought an example of a similar case - interviewing patients preparing for discharge from a rehabilitation hospital, with the following items:

walking;

climbing stairs;

carrying 5 pounds;

reaching for a phone;

dressing (putting on a shirt);

getting in and out of a car.

Each of these items is presented in terms of a multiple-choice ordinal scale.

We assume that the item from our Questionnaire:

What protective equipment and measures do you use when caring for livestock and cleansing premises for its maintenance?

with answer options:

Don't have farm animals (conditionally 1)

I carry out disinfection on my own using personal equipment (replaceable clothes, shoes) (conditionally 2)

I carry out disinfection myself using personal equipment (replaceable clothing, shoes + mask, gloves mandatorily) (conditionally 3)

Call disinfectors (conditionally 4)

is also presented as a kind of an ordinal scale from minimum to maximum

Other questions and variations of answers from the "Use of protective equipment and measures" domain can also be presented in the form of an ordinal scale, i.e. incrementally, for example:

Do you take part in a lambing, slaughtering animals, an autopsy of animals corpses, skinning animals?

No (don't have farm animals) (conditionally 1)

I do not hold farm animals, but sometimes I take part at the request of relatives or acquaintances (conditionally 2 )

Yes, on a regular basis (conditionally 3 ).

Do you use wool, hides, animal manure in everyday life?

(examples: use manure for the production of adobe or fertilize the garden; make products from hides or wool)

No

Sometimes, rarely

Yes.
Table 1. The variables (items)' mean values in the initial questionnaire. $\mathbf{N}$ observations: 55

\begin{tabular}{lcc}
\hline & Mean & SD \\
\hline $\begin{array}{l}\text { Do you own a livestock? Yes/No } \\
\text { Have you or someone from your family ever }\end{array}$ & 0.315 & 0.482 \\
had brucellosis? Yes/No & 0.133 & 0.340 \\
$\begin{array}{l}\text { If you or your relatives have had brucellosis, } \\
\text { have you practiced self-medication? Yes/No }\end{array}$ & 0.133 & 0.427 \\
$\begin{array}{l}\text { Do you use hides of animals in everyday } \\
\text { life? Yes/No }\end{array}$ & 0.167 & 0.373 \\
$\begin{array}{l}\text { Do you use the wool of animals in everyday } \\
\text { life? Yes/No }\end{array}$ & 0.233 & 0.423 \\
$\begin{array}{l}\text { Do you use animal manure to fertilize the } \\
\text { garden? Yes/No }\end{array}$ & 0.667 & 0.471 \\
\hline
\end{tabular}

The following guidelines were used during the results statistical processing:

1) Statsoft. Reliability and Positional Analysis. http://statsoft.ru/home/textbook/modules/streliab.html.

2) Portney LG, Watkins MP. Foundations of Clinical Research. Applications to Practice. 3rd ed. New Jersey: Pearson Education Inc. 2009. https://www.pearson.com/us/higher-education/program/PortneyFoundations-of-Clinical-Research-Applications-to-Practice-3rdEdition/PGM274308.html. 